\title{
A Review of Problem Structuring Methods for Consideration in Prognostics and Smart Manufacturing
}

\author{
Patrick T. Hester ${ }^{1}$, Andrew J. Collins ${ }^{2}$, Barry Ezell ${ }^{2}$, John Horst ${ }^{3}$ \\ ${ }^{1}$ Department of Engineering Management \& Systems Engineering, Old Dominion University, Norfolk, VA 23529 \\ pthester@odu.edu \\ 2 Virginia Modeling, Analysis, and Simulation Center, Old Dominion University, Suffolk, VA 23435 \\ ${ }^{3}$ Engineering Laboratory, National Institute for Standards and Technology (NIST), Gaithersburg, MA 20899
}

\begin{abstract}
Successful use of prognostics involves the prediction of future system behaviors in an effort to maintain system availability and reduce the cost of maintenance and repairs. Recent work by the National Institute of Standards and Technology indicates that the field of prognostics and health management is vital for remaining competitive in today's manufacturing environment. While prognostics-based maintenance involves many traditional operations researchcentric challenges for successful deployment such as limited availability of information and concerns regarding computational efficiency, the authors argue in this paper that the field of prognostics and health management, still in its embryonic development stage, could benefit greatly from considering soft operations research techniques as well. Specifically, the authors propose the use of qualitative problem structuring techniques that aid in problem understanding and scoping. This paper provides an overview of these soft methods and discusses and demonstrates how manufacturers might use them. An approach combining problem structuring methods with traditional operations research techniques would help accelerate the development of the prognostics field.
\end{abstract}

\section{INTRODUCTION}

In order to maintain U.S. industry competitiveness globally, the National Institute of Standards and Technology (NIST) has been working to advance measurement science standards. One specific thread NIST is focused on is Prognostics and Health Management for Smart Manufacturing Systems (PHM4SMS). The challenge associated with operating in increasingly complex

Patrick T. Hester et al. This is an open-access article distributed under the terms of the Creative Commons Attribution 3.0 United States License, which permits unrestricted use, distribution, and reproduction in any medium, provided the original author and source are credited. environments has been exacerbated in recent years. "Modern engineering systems and manufacturing processes are becoming increasingly complex, and are operating in highly dynamic environments. Thus, sustaining the reliability of such systems is becoming a more complex and challenging requirement" (Lee, Ghaffari, \& Elmeligy, 2011, p. 111). Prognostics and health management, specifically for smart manufacturing, is a promising area of research as a means for maintaining complex system reliability and for helping to make the U.S. succeed globally; however, it has yet to be universally embraced due to a number of factors that will be discussed later in this paper. We argue that prognostics and health management requires a preprocessing step, known as problem structuring, in order to allow it to reach its full potential.

To support this argument, this paper begins with an overview of prognostics and health management, followed by some issues, identified by researchers in the field that are inhibiting large-scale deployment. The paper then introduces problem structuring methods as a possible aid to limiting the effects of these issues. An overview of problem structuring methods is given, followed by a brief introduction to several popular methods. These methods are then applied to a notional smart manufacturing problem to demonstrate their potential. Finally, a recommendation is made regarding the use of problem structuring methods in conjunction with prognostics and health management techniques.

\section{Prognostics and Health Management}

Acclaimed novelist Kurt Vonnegut perhaps said it best when he remarked "...everybody wants to build and nobody wants to do maintenance" (Vonnegut, 1990, p. 240). Building systems is often straightforward; keeping them operating is much more difficult. "Prognostics and health management (PHM) is an emerging engineering discipline that evaluates the reliability of a system within its actual 
life-cycle conditions in order to detect beforehand any upcoming failures and reduce risks" (Lee et al., 2011, p. 111). System health monitoring (SHM) is an effort to maintain the functional operation of a system by monitoring its performance, while also minimizing cost.

A reduction in performance leads to a need to perform maintenance, which can be separated into reactive or proactive, based on a taxonomy developed by Kothamasu, Huang, \& VerDuin (2006). While reactive maintenance is the historical paradigm for maintenance, it is not ideal. "The oldest and most common maintenance and repair strategy is "fix it when it breaks." The appeal of this approach is that no analysis or planning is required. The problems with this approach include the occurrence of unscheduled downtime at times that may be inconvenient, perhaps preventing accomplishment of committed production schedules" (Kothamasu et al., 2006, p. 1012). An improved approach focuses on proactive or planned maintenance, which can be separated into preventive and predictive maintenance. Preventive maintenance includes constant interval maintenance, age-based maintenance, and imperfect maintenance. Predictive maintenance, however, includes reliability-centered maintenance (RCM) and conditionbased maintenance (CBM).

Prognostics can be useful for predictive maintenance. Roemer et al. (2011) give an overview of the area:

Prognostics has received considerable attention recently as an emerging sub-discipline within SHM. Prognosis is here strictly defined as "predicting the time at which a component will no longer perform its intended function." Loss of function is oftentimes the time at which a component fails. The predicted time to that point then becomes the remaining useful life (RUL). For prognostics to be effective, it must be performed well before deviations from normal performance propagate to a critical effect. This enables a failure preclusion or prevention function to repair or replace the offending components, or, if the components cannot be repaired, to retire the system (or vehicle) before the critical failure occurs. Therefore, prognosis has the promise to provide critical information to system operators that will enable safer operation and more costefficient use. (p. 281)

Kothamasu et al. (2006) discuss the utility of prognostics:

The only way to minimize both maintenance and repair costs and probability of failure is to perform ongoing assessment of machine health and ongoing prediction of future failures based on current health and operating and maintenance history. This is the motivation for prognostics: minimize repair and maintenance costs and associated operational disruptions, while also minimizing the risk of unscheduled downtime. (p. 1012)

There are many different models used to conduct prognostics. Byington, Roemer, Kacprzynski, \& Galie (2002) introduced the oft-cited general hierarchy of prognostics approaches shown in Figure 1.

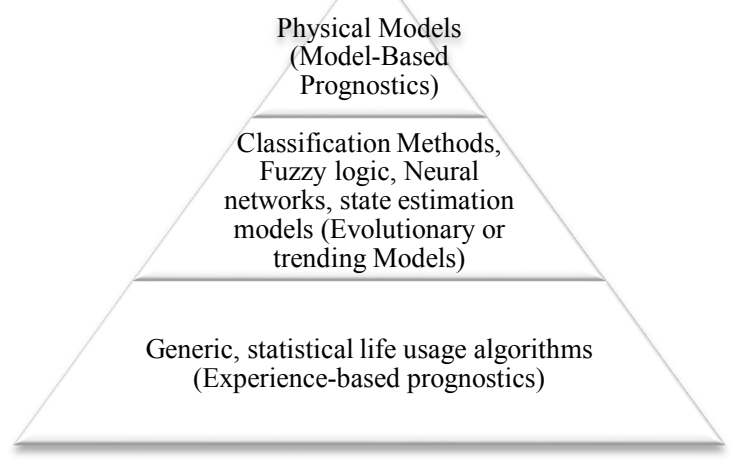

Figure 1. Hierarchy of Prognostics Techniques (adapted from Byington et al., 2002, pp. 6-2815)

In Figure 1, as we progress up the pyramid, techniques increase in both cost and accuracy, while the range of system applicability reduces. Methods range from generic historical failure rate models to high-fidelity physics-driven models. While there has been considerable research in the field of PHM over the last fifteen years, many issues remain preventing their full-scale deployment in areas such as smart manufacturing.

\subsection{Issues with Prognostics and Health Management}

On paper, prognostics and health management fits the traditional operations research paradigm. We have a problem of ensuring systems can remain fully functional while minimizing maintenance costs that appears clear cut and solvable using traditional mathematical models. However, several problems with development of a general prognostics approach exist. "Issues in the development and maintenance of prognostic systems include the selection of knowledge acquisition and modeling technologies, with considerations including available types of knowledge and approaches to achieve and maintain accuracy of the models and knowledge bases" (Kothamasu et al., 2006, p. 1021).

Further, prognostics research is still very much in development. "Unlike numerous methods available for diagnostics, prognostic methods are still in their infancy and literature is yet to present a working model for effective prognostics" (Mullera, Marquez, \& Iung, 2008, p. 1173). Further, "...there is still no universally accepted systematic methodology for prognostics research." (Lee et al., 2011, p. 112). Thus, prognostics approaches must be systemspecific; different "PHM systems typically have different 
performance requirements" (Zhou, Bo, \& Wei, 2013, p. 281).

Different stakeholders within a given prognostics and health management effort exist. Wheeler, Kurtoglu, \& Poll (2011) identify the main health management stakeholders as operations, regulatory, and engineering, while Saxena et al. (2008) identified diverse end users of prognostics metrics such as program managers, plant managers, operators, maintainers, and designers. Each of these end users has unique goals and metrics. The perspectives of these two papers were combined and shown in Table 1.

\begin{tabular}{|l|l|l|}
\hline Category & End User & Goals \\
\hline \multirow{4}{*}{ Operations } & $\begin{array}{l}\text { Program } \\
\text { Manager }\end{array}$ & Economic viability \\
\cline { 2 - 3 } & Plant Manager & $\begin{array}{l}\text { Resource allocation and } \\
\text { missing planning }\end{array}$ \\
\cline { 2 - 3 } & Operator & Plan execution \\
\cline { 2 - 3 } & Maintainer & $\begin{array}{l}\text { Downtime reduction and } \\
\text { availability maximization }\end{array}$ \\
\hline \multirow{2}{*}{ Engineering } & Designer & $\begin{array}{l}\text { Implement prognostic } \\
\text { system }\end{array}$ \\
\cline { 2 - 3 } & Researcher & $\begin{array}{l}\text { Develop and implement } \\
\text { performance assessment } \\
\text { algorithms }\end{array}$ \\
\hline \multirow{2}{*}{ Regulatory } & Policy Makers & $\begin{array}{l}\text { Assess potential hazards } \\
\text { and establish policies to } \\
\text { minimize effects }\end{array}$ \\
\hline
\end{tabular}

Table 1. Prognostics' End Users and Accompanying Goals (adapted from Saxena et al. (2010))

Table 1 shows a clear distinction in the goals of the varied end users of a prognostics' system. Further, even within a given health management system, stakeholders do not agree on system objectives (Wheeler et al., 2011). In fact, Wheeler et al. (2011) report, "some of the most interesting information is in the gap between user goals and the success metrics associated with diagnostics and prognostics" (p. 17). Thus, even within a given PHM effort, a single system may be insufficient to meet all user needs. As a result of these conflicts and the complications they form, researchers tend to avoid including all factors in their quantitative models; for example, Vandawaker, Jacques, \& Freels (2015) focused only on utilization, and ignored cost, in their research into uncertainty of system health monitoring for an aircraft fleet.

Each of these symptoms, issues with model development and accuracy due to extreme uncertainty, lack of a universal method, and divergent stakeholders, points to a need to invoke problem structuring methods (PSMs). Rosenhead (2006) discusses the situations for which PSMs are advantageous as those having: multiple actors, differing perspectives, partially conflicting interests, significant intangibles, and perplexing uncertainties. What exactly are PSMs? We now turn our attention to this question.

\section{Problem Description}

To give the reader some understanding of PSMs, we use an appropriate example problem in this paper to provide some context of how they might be applied. The example problem we will explore was introduced by Chien and $\mathrm{Wu}$ (2003). In this scenario, a semiconductor manufacturer is conducting final tests on integrated circuit (IC) devices. The final test results indicate whether to accept or reject an IC device. The goal is to make appropriate "decisions concerning site closure or machine repair with respect to increasing testing profit and maintaining customer satisfaction" (Chien \& Wu, 2003, p. 704). There are many factors involved, "including the test profit, cycle time, overdue cost, and the loss of falsely failed chips" (Chien \& Wu, 2003, p. 704). This problem is an ideal smart manufacturing application that enables the use of prognostics and health management to maintain site productivity and goals. Based on the underlying problem structure, decision makers can analyze the problem differently and in fact, Chien and $\mathrm{Wu}$ (2007) argue, are answering fundamentally different questions. What is the problem to be solved? This question is the driving force behind the development of problem structuring methods.

\section{Problem Structuring}

Ideally, a manufacturer would like their production line to be "faster, better, and cheaper." However, in the real world these attributes are usually in conflict with each other, e.g., a better quality product might cost more money to produce, producing the product faster might result in less quality control and, thus, a worse quality product, etc. An efficiently run manufacturing plant cannot have everything and sacrifices must be made to reduce cost; this includes which KPIs to monitor and which to not. Thus, KPIs should reflect the businesses strategy of the associated organization to enact its mission.

Not all KPIs will be appropriate for all business strategies. For example, if a business decision is made to run a product line until the machine fails, so choosing not to replace it, then knowing the man-hours used on maintenance is a meaningless KPI (as it should be zero hours). A more appropriate KPI would be "estimate date till complete failure." Similarly, if a manufacturer is not concerned about the quality of their product (i.e., their business model is focused on price rather than quality), then knowing the quality of the output to within $\pm 0.00001 \%$ accuracy is excessive; they may be fine with $\pm 1 \%$ or even $\pm 10 \%$.

A typical business has a lot of things to consider with their strategic planning: estimating market demand, satisfying customer requests, expansion/contraction plans, manpower 
planning, etc. These complex pressures are not usually reflected in the academic literature's manufacturing case studies due to parsimony reasons. However, it is precisely these complexities that make it difficult to know what KPIs a manufacturer should use and why PSMs are important in this selection because they bring clarity to the managers' understanding of their needs.

Where a PSM approach excels is in situations that involve more than one decision maker, typical of most complex organizations. The reason for this is that people tend to assume that everyone has the same understanding of the business as they do, and PSMs tend to bring to light these differences. A classic undergraduate case study that reflects this reality is the Rochem case (Slack, Chambers, \& Johnston, 2013, p. p. 247). The authors initially pose the case study as a simple decision to replace a food preservative manufacturing machine. The choices are the new version of the old machine or one with greater capacity and quality. However, a deeper read of the information reveals that a deep divide exists between two of the managers; the chief scientist wants a larger capacity machine because he believes that a new market is going to open up, whereas the marketing manager wishes to phase out the product in light of the company's other more success products. The outcome of the case study is that Rochem cannot make a decision until more information is known. Though the case study is about machine replacement, it can easily be envisioned that this uncertainty could occur in KPI selection. In both cases, PSMs can help zero in on the precise problem to be solved.

While much of the prognostics and health management literature addresses errors in some form (e.g., Saxena et al., 2008; Saxena et al., 2010; Wheeler et al., 2011), this discussion tends to focus on model error, prediction error, or sampling errors. While each of these errors are important, they are irrelevant if we do not first identify the correct problem. Other authors have called solving the wrong problem precisely a Type III error (Mitroff, 1998; Mitroff \& Featheringham, 1974; Mosteller, 1948). Research has shown the importance of focusing on avoiding the Type III error before worrying about any of the aforementioned errors (Adams \& Hester, 2012, 2013; Hester \& Adams, 2014). This is not a novel idea to practitioners. "The risk of solving the "wrong problem" is generally acknowledged and discussed by practitioners" (Woolley \& Pidd, 1981, p. 197). Yet, we often fail to correctly identify a problem before attempting to address it. Why? "Three principal reasons why persons fail to [accurately identify] problems and their causes are: (1) the problem solver doesn't actually perceive the problem - he is blind to it; (2) the wrong problem or the wrong causes of it (or both) are identified; and (3) the problem identification phase is skipped over and ignoredefforts are immediately made to solve "the problem."” (Watson, 1976, p. 88). Blanchard (2004) echoes the prevalence of the third cause: "Defining the problem is sometimes the most difficult part of the process, particularly if one is in a rush to 'get going"' (p. 48). Hammond, Keeney, and Raiffa (2002), too, warn of the pitfalls in taking problem formulation lightly:

Too often, people give short shrift to problem
definition...In their impatience to get on with
things, they plunge into the other elements of
decision making without correctly formulating the
problem first. Though they may feel like they're
making progress in solving their problem, to us
they seem like travelers barreling along a highway,
satisfied to be going 60 miles an hour--without
realizing they're going the wrong way. (p. 26)

Why is articulating the correct problem so important? Hammond et al. (2002) succinctly state it as, "The way you state your problem frames your decision. It determines the alternatives you consider and the way you evaluate them. Posing the right problem drives everything else" (p. 15). It's as simple as that. Ezell and Crowther (2007) identify five philosophical issues that may bias problem formulation: (1) hidden bias; (2) education bias; (3) understanding of reality; (4) perspective mismatch among the client and problem solver; and (5) confusion in the model and the real world. Incorrect identification of our problem increases the likelihood of us committing a Type III error. Fortunately, however, there are a suite of techniques known as problem structuring methods that can assist in this process.

Before proceeding, it is important to note here that problem structuring methods are different from decision-making methods. Decision-making methods are focused on making decisions about an already specified problem. Though related, diagnosing a problem based on historical case studies, like Katsouros, Papavassiliou, \& Emmanouilidis (2013) is not problem structuring because it assumes that the problem is already known and understood; it just has to be selected from a subset of known problems and, thus, can more readily been seen as the first step in a decision-making process. Problem structuring methods are used when the problem is not well-known or understood. Decision-making processes tend to be quantitative in nature, e.g., markov decision processes (Bole et al., 2015), whereas problem structuring methods are qualitative. Many prognostic techniques are focused on supplying information for decision-making techniques, e.g., Vandawaker, Jacques and Freels (2015), which assumes you know what information to collect in the first place.

\subsection{What are problems structuring methods?}

Problem structuring methods are part of what is termed soft OR (operations research). "The word hard refers to the use of mathematical and quantitative techniques...The soft in soft OR simply refers to the orientation of the approach as 
qualitative or interpretative rather than quantitative, as is the focus of hard OR... In very general terms, therefore, soft OR methods are those that structure a problem, as opposed to hard OR that seeks to solve it." (Heyer, 2004, pp. 2-4). Optimization and decision analysis, for example, are considered traditional hard OR techniques. The main soft OR techniques include Soft Systems Methodology, cognitive mapping, and Strategic Options Development and Analysis (SODA), which will be introduced in this section. Soft OR techniques, of which problem structuring is a part, should be thought of as working in concert with hard OR techniques and not in opposition to. "Problem structuring can be defined as the process of arriving at a sufficient understanding of a particular problem so as to proceed to some sort of formal modelling" (Pidd \& Woolley, 1980, p. 1063).

Problem structuring methods, as their name suggests, are focused on helping a decision-maker identify what the problem actually is (Collins \& Currie, 2012). To those with little practical experience, especially students, this statement might seem trivial because they are used to being presented well-structured problems to investigate. However, the realworld is full of problems that have not been explicitly stated, problems that can be described as messy. Vennix (1996) discusses these messy problems:

One of the most pervasive characteristics of messy problems is that people hold entirely different views on (a) whether there is a problem, and if they agree there is, and (b) what the problem is. In that sense messy problems are quite intangible and as a result various authors have suggested that there are no objective problems, only situations defined as problems by people. (p. 13)

Problem identification in these problems has only grown more difficult as problems have expanded in complexity. "In the 1970s, 80s and 90s, it had become obvious that some [organizational] problems could not be solved by pure logic, employing hard OR. Indeed problems have continued to become more complex and increasingly difficult to model mathematically" (Heyer, 2004, p. 3).

In the earlier semiconductor manufacturer example, customer satisfaction is stated as being one of the factors that will influence the maintenance schedule, which assumes the manufacturer knows what will satisfy their customers. If they do not know what would satisfy their customers, how would they find out? Do the customers prefer timeliness to quality? Does ensuring a high quality yield open up new customers to the manufacturer? Answers to these preliminary questions help the manufacturer make decisions regarding their maintenance schedule.

What the example above highlights is that on the surface a problem might seem straightforward, e.g., what should the maintenance schedule be, but may actually turn out to be far more complicated when the information requirements are thought through and might even highlight a gap in the manufacturer's strategic plans (Chapman \& Ward, 2002). Problem structuring methods are tools to help work through these issues and actually understand what the problem is. As the twentieth century American engineer Charles Kettering once said "a problem well stated is a problem half solved." Sadly, modern academic engineering has forgotten this advice though some academics have recently advocated for a renewed focus on problem structuring in academia and engineering (Blockley \& Godfrey, 2000; Hester \& Adams, 2014; Mingers, 2009).

The reason for an avoidance of problem structuring methods, beyond not being quantitative, is due the stovepiping of engineering techniques. The information gained from a PSM might result in a variety of hard methods being employed or even a trivial solution. From our example, if the customer's focus is timeliness, then the maintenance schedule becomes a minimization problem; if they require quality, then the maintenance schedule becomes a quality control problem; it might even turn out that the "fix it when it breaks" solution is appropriate for the business. A more likely scenario is that the solution method might be a mix of these factors, quality and timeliness, resulting a complicated solution approach. This may even lead to difficult questions for the business leaders, for example, if only $10 \%$ of revenue comes from customers that care about quality should we stop trying to satisfy those customers?

In short, a decision-maker might know that there is a problem, they just do not know what it is (Collins \& Currie, 2012). The problem might even involve intangible issues, for example, how will the maintenance schedule affect worker morale? Research into difficult problems has led to the term "wicked problems." Wicked problems are problems which are hard to solve because they lack complete information, their feasible solutions are not testable, and they are unique (Rittel \& Webber, 1973). As traditional hard OR was unable to tackle these wicked, or messy, problems, soft OR was developed. As wicked problems are hard to classify, Bayesian inference approaches, like the one proposed by Katsouros Papavassiliou, \& Emmanouilidis (2013) to address complex maintenance scenarios, are difficult to apply.

In the same way that a hammer makes it easier for us to put nails into wood, PSMs help our brain begin to understand these wicked problems. The limitation of the human brain can be seen by the amount of information that we can focus on at once (Miller (1956) famously showed that we could only handle approximately seven items at once). PSMs provide a set of tools to help us think about a problem in a structured way through a structured discussion. We use mind tools in our everyday life, for example, if you do not wish to forget something for work, place it by the front door the night before (Allen, 2002). However, unlike many hard techniques, PSMs do not guarantee that the "correct" solution will be found; as Collins and Currie (2012) state, "In the same way that having a hammer available does not 
guarantee that shelving will be [put up] straight, PSM does not guarantee a good, or even correct, model but it does provide a method, a hammer, to getting the modeling job done" (p.170). As use of a PSM does not guarantee a solution, research into PSMs tends to focus on the process of decision-making as opposed to the decision itself. Even if a solution was not found using a PSM, the processes provide a method for clarifying the problem and capturing viewpoints.

\subsection{Common Problem Structuring Methods}

This section introduces two PSMs, namely: strategic options development and analysis (SODA) and soft systems methodology (SSM). The methods were chosen because of their simplicity as this paper is intended for a reader not familiar with PSMs, as well as their prominence within the literature (Mingers, 2011). The underlying diagrammatic method for each of these methodologies are described by Mingers (2011) and Ackermann (2012) as cognitive mapping (for SODA) and rich pictures (for SSM). Other approaches do exist, for example, drama theory (Bryant, 2007), morphological analysis (Ritchey, 2006), dialogue mapping (Conklin, 2005), strategic choice approach (Friend \& Hickling, 1987; Friend \& Jessop, 1977), and systemic thinking (Hester \& Adams, 2014). This is not an exhaustive list but represents examples of PSMs that have been practical implementation.

\subsubsection{Strategic Options Development and Analysis}

Strategic Options Development and Analysis (SODA) is a specific technique based on cognitive mapping developed to tackle wicked problems by Colin Eden (2001). Cognitive mapping is simple to understand but it also provides a powerful tool to understanding a problem due to its focus on capture ideas in a non-linear way. The traditional approach to capturing ideas is done in a linear, sequential manner such as bullet-point lists or prose. Cognitive mapping allows for the connection of ideas, using arcs and arrows, to produce an overall linkage map that gives a holistic view of the problem that might not have been apparent before the cognitive mapping exercise. It also highlights what has been the focus of the discussion, since those areas will be well represented on the map. An example cognitive mapping can be seen in Figure 2, which is based on our semiconductor manufacturing example.

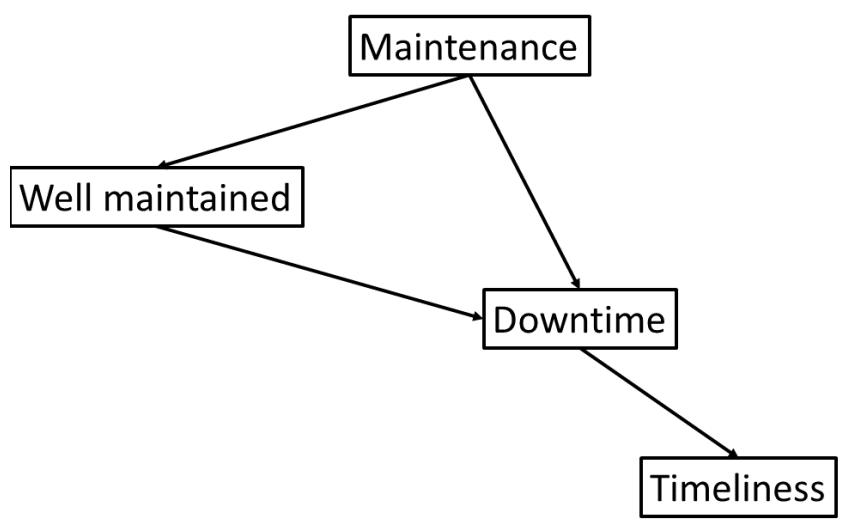

Figure 2. Partial cognitive map of example semiconductor problem

The concepts in the nodes can be anything: an event, a physical quality, an intangible state, etc. The arrows show that the concept in one node affects the concept in the connected node. As Collins and Currie state, "The purpose of cognitive maps are to allow the user to visualize the abstract system under consideration and guide them to making decisions relating to the system; this can be seen in the same way as how geographic maps help when deciding on which route to take on a journey" (Collins \& Currie, 2012, p.170).

SODA requires concepts to be connected by a positive or negative arrow, whereas cognitive mapping does not. A positive arrow implies that the concept has a positive, or beneficial, impact on the linked concept, whereas a negative arrow implies a negative, or detrimental, impact. To understand how these links work, consider again our semiconductor manufacturing example: maintenance has a positive impact on downtime, i.e., increases it, because the manufacturing process has to stop for maintenance, so a positive arrow would connect the two concepts. Downtime decreases the manufacturer's ability to complete orders on time so a negative arrow would be used to connect downtime to timeliness. However, better maintained machines are less likely to break down so "well maintained" is has a negative impact on downtime, i.e., deceases it, due to less failures. These relationships are shown in Figure 3.

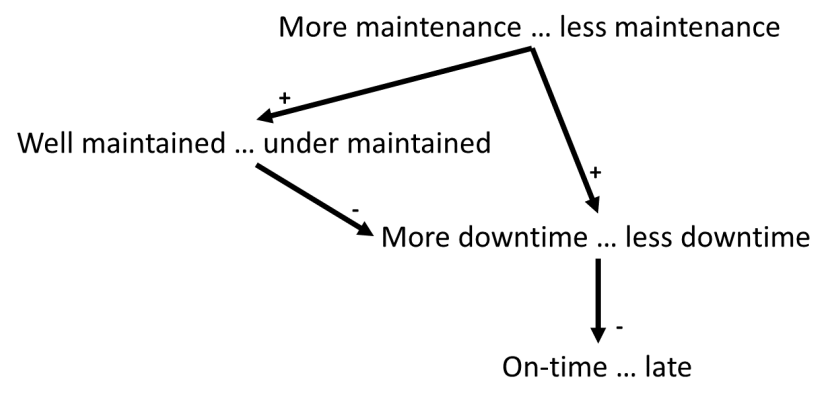

Figure 3. Example of cognitive map used in SODA 
The figure shows that the concepts have been placed in a positive-negative arrangement. A positive (negative) arrow from $\mathrm{X}$ to $\mathrm{Y}$ mean that the more there is of $\mathrm{X}$ the more (less) there is of $\mathrm{Y}$, based on the continuum shown in the node. This is supposed to represent how the concept can change. For example, the system might have more maintenance or less maintenance. The ellipses are equivalent to "as opposed to." A criticism of adding concepts this way is that it is subjective. For example, the figure could depict "early" instead of "on time" in the lowest concept of Figure 3. SODA only provides a representation of the problem in a diagrammatic form, and no further analysis is provided, unlike other approaches, like systems dynamics, which would develop a quantitative model from the diagram. The goal of the SODA process is to highlight weaknesses of understanding, as well as to provide a common understanding of the problem among stakeholders.

\subsubsection{Soft Systems Methodology}

Another approach to deal with wicked problems, Soft Systems Methodology, was developed by Peter Checkland (Checkland \& Scholes, 1999). Checkland's approach was developed from direct experiences with industrial projects. SSM is a process-based approach. The seven steps of the process can be summarized as:

1. A problem situation occurs.

2. The problem situation is expressed.

3. Root definitions of relevant purposeful activity systems.

4. Conceptual model derive from step three.

5. Comparison of models and real world.

6. Identifying changes that are desirable and feasible.

7. Take actions to improve problem situation.

A first glance, these steps may seem straightforward, which is testimonial to the validity of Checkland's design, but each step must be carefully considered for information extraction to be achieved. For example, it can be hard to find a root definition of the system so Checkland purposes using the CATWOE technique, which stands for Customers, Actors, Transformation Process, World View, Owner, and Environmental Constraints. CATWOE is a series of questions which the stakeholders must answer to have a definition of the system. An interesting part of the SSM process is the movement from the real-world to the abstract and back to the real-world; this allows the decision-makers to focus their discussion in a particular domain and avoid a large spread in conversation. As the reader might imagine, the SSM process requires a skilled facilitator to function efficiently. The reason for facilitation is that SSM approach uses model building to build consensus.

Although they are really intended to help stakeholders understand and articulate the problem situation (primarily steps 1 and 2), rich pictures are arguably the most used element of SSM (C. Eden \& Ackermann, 1998). Ackermann (2012) describes them as:

The rich picture, which may be seen as a 'cartoonlike' representation of the problem situation as a whole, is used to reveal the processes, structures, burning issues (particularly human), flows etc. and acts as a powerful dialectic for conversation and subsequent learning. It aims to provide a view of the current situation and therefore can be a cathartic mechanism allowing concerns to be aired. (p. 653)

The construction of rich pictures follows no common syntax or technique but rather it is intended to be a graphical representation of whatever level of detail is deemed necessary to facilitate further understanding about a problem situation. One common technique is to have those stakeholders affiliated with a problem independently generate a rich picture and compare their representations in an effort to generate discussion and produce a common understanding of a problem situation. An example of this situation is shown in Figures 4 and 5 for a consumer and manufacturer, respectively.

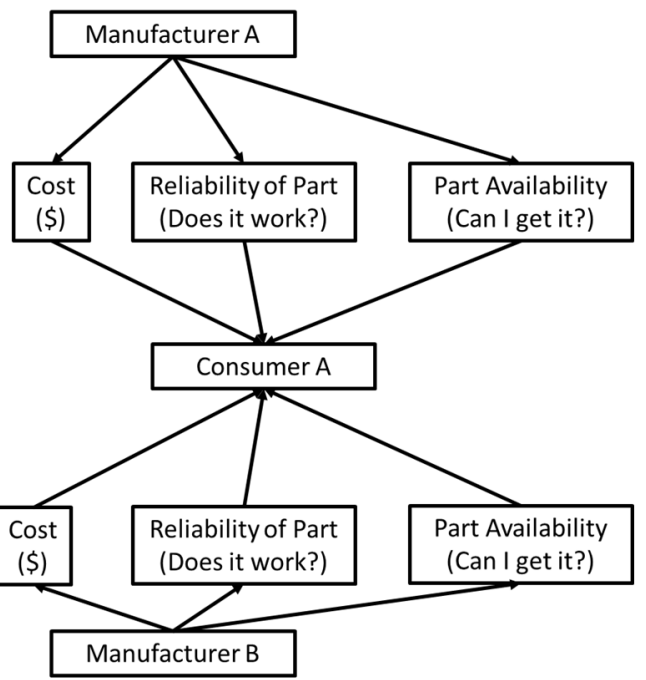

Figure 4. Rich picture from consumer's perspective

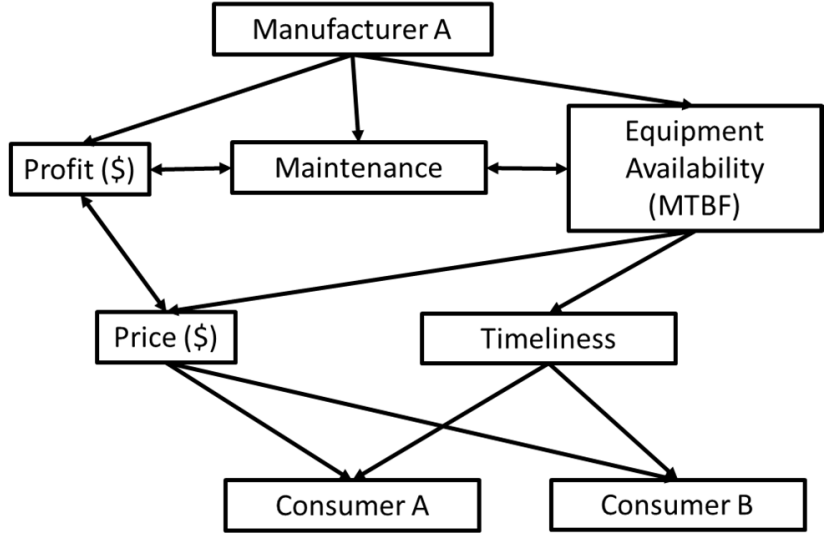

Figure 5. Rich picture from manufacturer's perspective 
The differences between perspectives in Figures 4 and 5 are many. From Figure 4's perspective, the consumer is concerned with cost, measured (how much will it cost me), part reliability (does the item work when I want it to), and part availability (can I get the part when I go to the store). These are all non-technical perspectives and the consumer views the problem as one in which manufacturers are competing for their business. An alternative viewpoint is that of the manufacturer, as shown in Figure 5. This perspective is far more technical. It involves consideration of profit, which is a function of both part price and maintenance costs (among other factors), as well as equipment availability (measured in mean time between failure (MTBF)). MTBF affects both timeliness and price. The manufacturer sees their problem as one in which numerous consumers evaluate their product based on price and timeliness (availability). Maintenance procedures are linked to both profit and MTBF, and policies for maintenance are far-reaching in their effect. Therein lies the potential justification for prognostics and health management techniques. Whereas the consumer does not care about how the product gets to them, they just want it faster, better, and cheaper, as the old saying goes. The manufacturer must care about these elements if they wish to compete in a globally competitive landscape. Assessment of the differing rich pictures allows for a more complex understanding of the problem and depending on the primary proponent of the analysis, be it the manufacturer or the consumer, drives the ensuing SSM assessment in a completely different direction.

\subsection{Issues with the Use of Problem Structuring Methods}

Up until now we have highlighted the many advantages of the use of PSMs, however, it would be disingenuous to not also point out that there are some drawbacks. There is a contingent of researchers and practitioners within the operations research community that do not consider PSMs "real OR" (Mingers, 2011). This bias held by some in the OR community means that use of PSMs is often facing an uphill battle (Collins \& Frydenlund, 2015). In addition to this subjective impediment to the use of PSMs, three substantive issues present themselves when using problem structuring methods: 1) the difficulty in assessing the efficacy of methods, 2) the need for a skilled facilitator, and 3) difficulties associated with method selection itself.

The complexity of PSMs means it is difficult to assess whether or not a method has been deployed correctly. With a hard OR approach, we can quantify the effect gained from making a decision. For example, we can discern how much money we have saved by investing in a sophisticated prognostics system based on maintenance savings versus the cost of the system. However, as it pertains to PSMs, it is difficult to discern how we quantify the value of knowing whether we needed the system to begin with or whether we should reinvested in a new plant configuration (i.e., are we solving the right problem), although there has been some work illustrating successful PSM case studies (Mingers \& Rosenhead, 2004; Munro \& Mingers, 2002; Pidd \& Woolley, 1980; Rosenhead \& Mingers, 2001).

The role of the OR practitioner within a hard OR problem is first and foremost that of an analyst, reconstituting available data into a format suitable for further assessment, i.e., setting up a linear program to solve a scheduling problem. In soft OR, however, the OR practitioner is a facilitator, "attempting to manage the complexities and uncertainties of problem content while simultaneously managing the interpersonal processes and dynamics of the client group" (Rosenhead, 1996, p. 128). This is not to say the soft OR problem practitioner's job is more difficult than that of the hard OR analyst, just different. The skill set required is not traditionally taught in OR education, at least within the United States (Mingers, 2011).

Finally, method selection within soft OR can be difficult. There are many techniques, as discussed in this paper, and each has its own subtleties, advantages, and disadvantages, making method selection difficult (Mingers \& Rosenhead, 2004). We have introduced the reader to two methods and discussed their relevance in the prognostics and health management world. In the following section, we elaborate on the use of cognitive mapping to address a realistic problem.

\section{Example Problem}

In this section, we demonstrate the utility of applying problem structuring methods to a practical problem. The problem we investigate was introduced earlier in Section 3, as developed by Chien and $\mathrm{Wu}(2003)$. We will demonstrate cognitive mapping, the fundamental logic underlying the SODA approach in this section. The basic steps to be followed in developing a cognitive map amongst many stakeholders are (Hester, Akpinar-Elci, Shaeffer, and Shaeffer, In press):

1) Stakeholders decide on an issue (i.e., a variable of interest) to explore to provide a common anchor for their individual cognitive map (CM);

2) Each stakeholder independently develops a $\mathrm{CM}$ of the situation, including directionality (positive, negative, or unknown) linkages between concepts;

3) The stakeholder discuss their individual perspectives, using their $\mathrm{CM}$ as the common language of comparison;

4) Stakeholders are provided the opportunity to revise their CM based on the conversation in Step 3. Thus, they can return to Step 2 (or 1 if needed), or proceed to Step 5; 
5) A narrative is constructed to illustrate the similarities and differences between the perspectives; and

6) Although it will not be undertaken in this analysis, further analysis including fuzzification can be invoked using CM maps to determine dynamic behaviors (see, e.g., Kosko (1986)). This requires a consensus CM be generated. Given that the intent of this paper is to demonstrate utility of PSMs in a smart manufacturing environment, a narrative discussion is determined to be a sufficient stopping point.

Step 1: The example problem concerns a semiconductor manufacturer who is conducting final tests on integrated circuit (IC) devices (see Section 3 and Chien and $\mathrm{Wu}$ (2003) for further problem context). The final test results indicate whether to accept or reject an IC device. The variable of interest is the price of a particular part (as influenced by testing decisions). It is of interest to explore this variable from both the manufacturer and consumer's perspective.

Step 2: Figures 4 and 5 have been adapted to include directionality as representative viewpoints of the problem from the consumer and manufacturer's perspectives. These perspectives are shown in Figures 6 and 7, respectively.

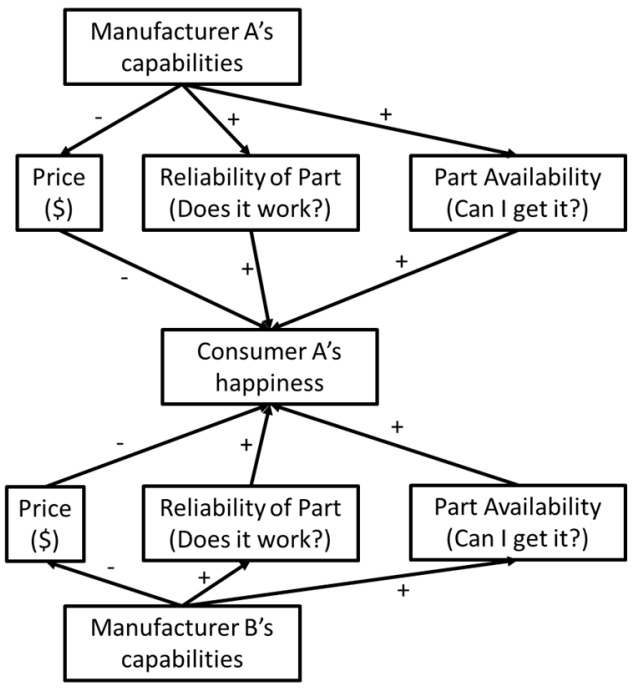

Figure 6. Cognitive map from consumer's perspective

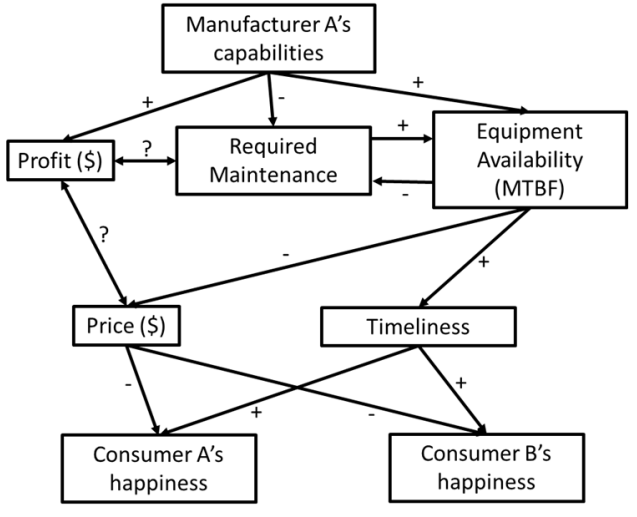

Figure 7. Cognitive map from manufacturer's perspective

Step 3: In this case, the manufacturer may hold a number of in-house meetings, as well as consumer focus groups, to understand their internal perspectives, as well as those of their customers. They can identify that price, for example, is a fundamentally important element in both the manufacturer's and consumer's cognitive maps. However, the consumer is also concerned with part availability and reliability, whereas the manufacturer is focused on price and timeliness. Seeing this, the manufacturer may wish, via Step 4, to modify their map to reflect common terminology, thus "Timeliness" in their cognitive map becomes "Part Availability" as this is the real concern of the consumer.

Step 4: The change from "Timeliness" to "Part Availability" is reflected in the consumer's cognitive map (not shown).

Step 5: The manufacturer's and consumer's perspectives are combined as shown in Figure 8. This perspective is more comprehensive and complete than either stakeholder viewed the problem to begin with (see Figures 6 or 7).

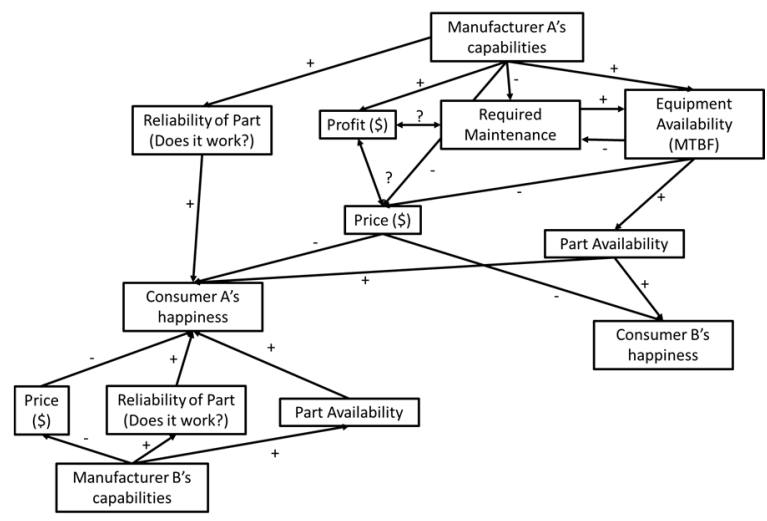

Figure 8: Combined Cognitive Map

Reflection by the manufacturer on the comprehensive problem mapping may cause a modification of its original intention. At the outset of the problem, the manufacturer identified price as the driver for their decisions. However, looking at Figure 8, we see the real problem is much more complex. Manufacturer A has to compete with Manufacturer B (and likely many others), while Consumer A must choose between numerous manufacturers. Each of the manufacturers is evaluated on a number of factors, of which price is only a singular element. As a result, Manufacturer A must be concerned with price, but there are still many uncertainties at play, including the relationship between price and profit and profit and required maintenance. Further evaluation might encourage the manufacturer to investigate maintenance procedures and policies, whereas the initial focus was on acceptance testing and accompanying profit. Clearly, the use of prognostics and health monitoring techniques could aid the manufacturer in reducing required maintenance and increasing profit, however, the linkage between their 
original problem and PHM may not have been so clear without the application of problem structuring methods. While this is a simple example, it shows the power of PSMs in helping to reveal additional details about the true nature of a problem facing an organization.

Though the approach of SODA and SSM may look simple from the outside (which they are designed to be to help facilitation of them), there are many issues not covered in this paper that a potential facilitator of the technique should be aware of. These issues are discussed in detail in Eden and Ackermann (1998) for SODA and Checkland \& Scholes (1999) for SSM. Both books are easily accessible to a beginner in the field, however, an in-depth exploration of their content is well beyond the scope of this paper. In the next section, we make suggestions as to how to embrace these methods moving forward.

\section{A Way Ahead}

This paper has introduced the reader to the utility of applying problem structuring techniques to prognostics and health management applications. While the use of PSMs alone has advantages, they are perhaps best used in concert with a hard OR technique (Munro \& Mingers, 2002). While such an approach is not without both philosophical and practical challenges (Kotiadis \& Mingers, 2006), many studies have shown advantages reported by practitioners (Mingers \& White, 2010; Munro \& Mingers, 2002; Rosenhead \& Mingers, 2001). To this end, we suggest methods reflected in Figure 1 should work with problem structuring methods as well. We believe that PSMs would work as a preprocessing step to those in Figure 1 because the problem must first be derived before prognostic techniques can be applied.

The proposed modification is meant to suggest that PSMs can (and should) work hand-in-hand with existing prognostics techniques by first defining the problem to be solved by traditional prognostic techniques. This enhanced approach can help both structure and solve difficult prognostics and health management problems and help researchers and practitioners focus their efforts on the areas most in need of further development, so as to avoid committing a Type III error in this exciting and emerging field. Our intent is that this paper serves as a call to arms for the prognostics and health management community to embrace PSMs in an effort to accelerate the PHM field's development. It is our belief that adoption of these techniques is vital for the United States to remain competitive in today's manufacturing environment.

\section{ACKNOWLEDGEMENT}

This work was undertaken as part of the National Institute for Standards and Technology (NIST) project entitled "Key performance indicators effectiveness for sensing and control smart manufacturing" award number 70NANB14H261.

\section{REFERENCES}

Ackermann, F. (2012). Problem structuring methods 'in the Dock': Arguing the case for Soft OR. European Journal of Operational Research, 219, 652-658.

Adams, K. M., \& Hester, P. T. (2012). Errors in systems approaches. International Journal of System of Systems Engineering, 3(3/4), 233-242.

Adams, K. M., \& Hester, P. T. (2013). Accounting for errors when using systems approaches. Procedia Computer Science, 20, 318-324.

Allen, D. (2002). Getting Things Done: The Art of StressFree Productivity: Penguin (Non-Classics).

Blanchard, B. S. (2004). Systems engineering management, $3 r d E d$. (3rd ed.). Hoboken, NJ: John Wiley \& Sons.

Blockley, D. I., \& Godfrey, P. (2000). Doing it differently: systems for rethinking construction. Thomas Telford.

Bole, B., K. Goebel and G. Vachtsevanos (2015). Controlling tracking performance for system health management - a markov decision process formulation. International Journal of Prognostics and Health Management 6: 1-9.

Bryant, J. W. (2007). Drama theory: dispelling the myths. Journal of the Operational Research Society, 58, 602613.

Byington, C. S., Roemer, M. J., Kacprzynski, G. J., \& Galie, T. (2002). Prognostic Enhancements to Diagnostic Systems for Improved Condition-Based Maintenance. Paper presented at the Aerospace Conference Proceedings.

Chapman, C., \& Ward, S. (2002). Managing Project Risk and Uncertainty: A Constructively Simple Approach to Decision Making (1st ed.). Chichester: Wiley.

Checkland, P., \& Scholes, J. (1999). Soft Systems Methodology in Action: Wiley.

Chien, C.-F., \& Wu, J.-Z. (2003). Analyzing repair decisions in the site imbalance problem of semiconductor test machines. IEEE Transactions on Semiconductor Manufacturing, 16(4), 704-711.

Chien, C.-F., \& Wu, J.-Z. (2007). Structuring manufacturing strategy. Paper presented at the Proceedings of the 3rd Annual IEEE Conference on Automation Science and Engineering, Scottsdale, AZ.

Collins, A. J., \& Currie, C. (2012). Operations Research. In J. A. Sokolowski \& C. M. Banks (Eds.), Handbook of Modeling and Simulation Real-world Applications (pp. 165-206). New York: Wiley.

Collins, A. J., and E. Frydenlund (2015). Academic revenue management and quantitative worship. Journal of Revenue \& Pricing Management 14(1), 50-56. 
Conklin, J. (2005). Dialogue mapping: Building shared understanding of wicked problems: John Wiley \& Sons, Inc.

Eden, C. (2001). SODA - The Principles. In J. Rosenhead \& J. Mingers (Eds.), Rational Analysis for a Problematic World Revisited (pp. 21-42). Chichester: Wiley.

Eden, C., \& Ackermann, F. (1998). Making strategy: The journey of strategic management. London: Sage.

Ezell, B.C. and Crowther, K.G. (2007). Philosophical issues and their implications for the systems architect. Foundations of Science, 12(3), 269-276.

Friend, J. K., \& Hickling, A. (1987). Planning under pressure: The Strategic Choice Approach. Oxford, UK: Pergamon.

Friend, J. K., \& Jessop, W. N. (1977). Local government and Strategic Choice (2nd. Ed.). Oxford, UK: Pergamon.

Hammond, J. S., Keeney, R. L., \& Raiffa, H. (2002). Smart choices: A practical guide to making better life decisions. New York: Broadway Books.

Hester, P. T., \& Adams, K. M. (2014). Systemic thinking: Fundamentals for understanding problems and messes. Cham, Switzerland: Springer International.

Hester, P. T., Akpinar-Elci, M., Shaeffer, J. M., \& Shaeffer, M. B. (In press). On complementarity and the need for a transdisciplinary perspective in addressing emerging global health issues. In F.-J. Kahlen, S. Flumerfelt, \& A. Alves (Eds.), Interdisciplinary perspectives on complex systems: New findings and approaches. Cham, Switzerland: Springer International.Heyer, R. (2004). Understanding Soft Operations Research: The methods, their application and its future in the Defence setting (DSTO-GD-0411). Edinburgh, Australia: DSTO Information Sciences Laboratory.

Katsouros, V., Papavassiliou, V. \& Emmanouilidis, C. (2013). A Bayesian approach for maintenance action recommendation. International Journal of Prognostics and Health Management, 4, 1-6.

Kosko, B. (1986). Fuzzy cognitive maps. International Journal of Man-Machine Studies, 24, 6575.Kothamasu, R., Huang, S. H., \& VerDuin, W. H. (2006). System health monitoring and prognostics-A review of current paradigms and practices. International Journal of Advanced Manufacturing Technology, 28, 1012-1024.

Kotiadis, K., \& Mingers, J. (2006). Combining PSMs with hard OR methods: The philosophical and practical challenges. Journal of the Operational Research Society, 57, 856-867.

Lee, J., Ghaffari, M., \& Elmeligy, S. (2011). Selfmaintenance and engineering immune systems: Towards smarter machines and manufacturing systems. Annual Reviews in Control, 35, 111-122.

Miller, G. A. (1956). The magical number seven, plus or minus two: some limits on our capacity for processing information. Psychological Review, 63(2), 81.
Mingers, J. (2009). Taming Hard Problems with Soft O.R. ORMS Today, 36, 48-53.

Mingers, J. (2011). Soft OR comes of age-But not everywhere! Omega, 39, 729-741.

Mingers, J., \& Rosenhead, J. V. (2004). Problem structuring methods in action. European Journal of Operational Research, 152, 530-554.

Mingers, J., \& White, L. (2010). A review of the recent contribution of systems thinking to operational research and management science. European Journal of Operational Research, 207, 1147-1161.

Mitroff, I. (1998). Smart thinking for crazy times: The art of solving the right problems. San Francisco, CA: BerrettKoehler Publishers.

Mitroff, I., \& Featheringham, T. R. (1974). On systematic problem solving and the error of the third kind. Behavioral Science, 19(6), 383-393.

Mosteller, F. (1948). A K-sample Slippage Test for an Extreme Population. The Annals of Mathematical Statistics, 19(1), 58-65.

Mullera, A., Marquez, A. C., \& Iung, B. (2008). On the concept of e-maintenance: Review and current research. Reliability Engineering and System Safety, 93, 11651187.

Munro, I., \& Mingers, J. (2002). The use of multimethodology in practice--results of a survey of practitioners. The Journal of the Operational Research Society, 53(4), 369-378.

Pidd, M., \& Woolley, R. N. (1980). A pilot study of problem structuring. The Journal of the Operational Research Society, 31(12), 1063-1068.

Ritchey, T. (2006). Problem structuring using computeraided morphological analysis. Journal of the Operational Research Society, 57(7), 792-801. doi:10.1057/palgrave.jors. 2602177

Rittel, H. W. J., \& Webber, M. M. (1973). Dilemmas in a general theory of planning. Policy Sciences, 4(2), 155169.

Roemer, M. J., Byington, C. S., Kacprzynski, G. J., Vachtsevanos, G., \& Goebel, K. (2011). Prognostics. In S. B. Johnson, T. J. Gormley, C. Mott, S. S. Kessler, A. Patterson-Hine, K. M. Reichard, \& J. Philip A. Scandura (Eds.), System Health Management: with Aerospace Applications, . Chichester, UK: John Wiley $\&$ Sons.

Rosenhead, J. V. (1996). Whats the problem? An introduction to problem structuring methods. INTERFACES, 26(6), 117-131.

Rosenhead, J. V. (2006). Past, present and future of problem structuring methods. Journal of the Operational Research Society, 57, 759-765.

Rosenhead, J. V., \& Mingers, J. (2001). Rational analysis for a problematic world revisited (2nd edition). Chichester, England: Wiley \& Sons.

Saxena, A., Celaya, J., Balaban, E., Goebel, K., Saha, B., Saha, S., \& Schwabacher, M. (2008). Metrics for 
Evaluating Performance of Prognostics Techniques. Paper presented at the 1 st International Conference on Prognostics and Health Management (PHM08), Denver, CO.

Saxena, A., Celaya, J., Saha, B., Saha, S., \& Goebel, K. (2010). Metrics for Offline Evaluation of Prognostic Performance. International Journal of Prognostics and Health Management, 1, 1-20.

Slack, N., Chambers, S., \& Johnston, R. (2013). Operations management (7th ed.). Harlow, UK: Pearson education.

Vennix, J. (1996). Group model building: Facilitating team learning using system dynamics. Chicester, UK: John Wiley \& Sons.

Vandawaker, R.M., Jacques, D.R. \& Freels, J.K. (2015). Impact of prognostic uncertainty in system health monitoring. International Journal of Prognostics and Health Management, 6, 1-13.
Vonnegut, K. (1990). Hocus pocus. New York: Putnam Publishing Group.

Watson, C. E. (1976). The Problems of Problem Solving. Business Horizons, August, 88-94.

Wheeler, K. R., Kurtoglu, T., \& Poll, S. D. (2011). A Survey of Health Management User Objectives in Aerospace Systems Related to Diagnostic and Prognostic Metrics. International Journal of Prognostics and Health Management, 1, 1-19.

Woolley, R. N., \& Pidd, M. (1981). Problem Structuring -A Literature Review. The Journal of the Operational Research Society, 32(3), 197-206.

Zhou, Y., Bo, J., \& Wei, T. (2013). A Review of Current Prognostics and Health Management System Related Standards. Chemical Engineering Transactions, 33, 277-282. 